\section{Capturing clouds}

Geophys. Res. Lett.

doi:10.1029/2008GL035846(2008)

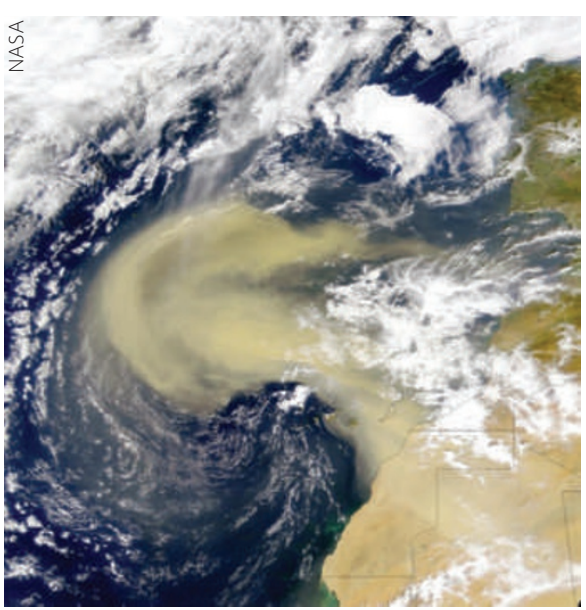

Dust from the Sahara can directly drive the formation of cloud droplets over the eastern North Atlantic Ocean. Previously, dust was only known to trigger icecrystal nucleation or to produce liquid droplets after undergoing substantial atmospheric processing.

Cynthia Twohy of Oregon State University and colleagues analysed the contents of clouds over the eastern North Atlantic Ocean. They found considerable quantities of dust particles in small clouds, with up to $80 \%$ of the sampled droplets containing dust. As dust naturally contains small amounts of material that can interact with water, these particles can be crucial in the formation of clouds, even near their source.

The authors suggest that the infusion of Saharan dust into clouds could enhance albedo, decrease precipitation in shallow clouds and alter ice formation in deep clouds; these effects will be exacerbated if dust emissions increase as a result of changes in land use and climate.

\section{A history of calcium}

Science doi:10.1126/science.1163614 (2008)

Although calcium is thought to be conservative in the oceans, ancient marine sediments suggest that the isotopic composition and concentration of dissolved calcium has varied dramatically over the past 28 million years. The marine calcium-cycle is controlled by the balance between continental and hydrothermal inputs, and removal by carbonate deposition and alteration of oceanic crust.

Elizabeth Griffith at Stanford University and colleagues measured the isotopic composition of calcium ions in barite crystals recovered from marine sediments. In this way, the team reconstructed the calcium isotope history of the oceans, free from artefacts of changing carbonate chemistry or biological processes. The data show a number of abrupt shifts in calcium cycling.

The largest increase in oceanic calcium-ion concentrations occurred 13 million years ago, in association with decreasing global temperatures. The growth of ice sheets and the subsequent drop in sea level at this time may have enhanced carbonate rock weathering, thereby increasing calcium flux to the oceans.

\section{Martian glaciers}

Science 322, 1235-1238 (2008)

Lobe-shaped features, reminiscent of glacial deposits on Earth, fringe the high-relief terrains dotting the midlatitudes of Mars. New data suggest that these lobes consist almost entirely of water ice covered by a relatively thin layer of rock debris.

John Holt at the University of Texas in Austin and colleagues analysed radar images obtained by the Mars Reconnaissance Orbiter, which began searching for evidence of water on Mars in 2006. Although the team identified some layering at the base of the lobate features, they conclude that the deposits are mostly homogeneous and consist of water ice. As these lobate features are present throughout many of Mars's temperate regions, they may constitute a sizeable water reservoir.

Like Earth, Mars also undergoes climate changes in response to variations in its orbit round the sun. The researchers suggest that these 'glaciers' may be remnants of a martian ice-age.

\section{Missing methane source \\ Earth Planet. Sci. Lett.}

doi:10.1016/j.epsl.2008.10.022 (2008)

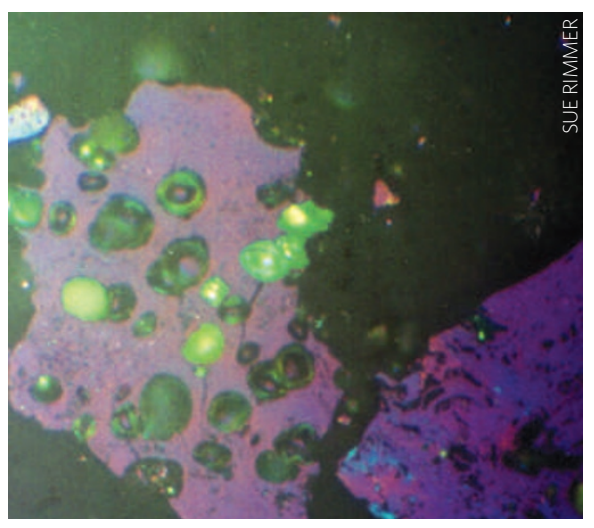

A large negative shift in the carbon isotope reservoir during the Early Jurassic period has been ascribed to a massive release of methane. It had been suggested that the methane could have arisen from magma that intruded into coals beds in the Karoo-Ferrar large igneous province, but new compositional data reveal little evidence for such an event.

Darren Gröcke from Durham University, UK and colleagues analysed the carbon isotope composition of coal along the margins of sheet-like bodies of magma that intruded into coal beds in the Karoo region of South Africa. They found that although the fraction of volatile matter in the coals decreased adjacent to the intrusions, the carbon isotope ratios did not change significantly, indicating that little or no methane was generated.

The researchers conclude that much of the heat provided by the intrusions would have been consumed by heating the pore water within the coal beds and sedimentary rocks surrounding the intrusions.

\title{
Nevada on the slide
}

The behaviour of the lithosphere in the western United States - which is currently undergoing regional-scale deformation - remains a subject of debate. The crust underlying this region may be slowly sliding along an eastward-sloping surface, in a motion opposite to the underlying upper mantle.

Brian Wernicke of the California Institute of Technology and colleagues compiled geological information, GPS data and seismic images for the western United States. The data suggest that in response to regional extension, a large portion of the crust in the Nevada region is sliding along the crust-mantle boundary, some $30 \mathrm{~km}$ below the Earth's surface. The researchers propose that the surface between the detaching crust and the mantle is analogous to the interface between a subducting slab and the overlying plate.

Since 1998, the net movement along the detachment was 5-10 mm. The energy released by this long-term slow slip is equivalent to that released during a magnitude-seven earthquake. 